\title{
Temporal and Spatial Seasonal Variations in Quality of Gravity Flow Water in Kyanamira Sub-County, Kabale District, Uganda
}

\author{
Hannington Ngabirano ${ }^{1}$, Denis Byamugisha², Emmanuel Ntambi² \\ ${ }^{1}$ Department of Chemistry, Faculty of Science, Kabale University, Kabale, Uganda \\ ${ }^{2}$ Department of Chemistry, Mbarara University of Science and Technology, Mbarara, Uganda \\ Email: *ngabiranoh@gmail.com, ^hngabirano@kab.ac.ug
}

How to cite this paper: Ngabirano, H., Byamugisha, D. and Ntambi, E. (2017) Temporal and Spatial Seasonal Variations in Quality of Gravity Flow Water in Kyanamira Sub-County, Kabale District, Uganda. Journal of Water Resource and Protection, 9, 455-469.

https://doi.org/10.4236/jwarp.2017.95029

Received: January 7, 2017

Accepted: April 17, 2017

Published: April 20, 2017

Copyright $\odot 2017$ by authors and Scientific Research Publishing Inc. This work is licensed under the Creative Commons Attribution International License (CC BY 4.0).

http://creativecommons.org/licenses/by/4.0/

\begin{abstract}
The study was designed to investigate temporal and spatial seasonal variations in quality properties of gravity flow water samples collected from Kigata, Kacuro, Kihanga, Kitibya and Kanjobe located in Kyanamira Sub-County, Kabale District, Uganda. Physical, chemical and biological parameters such as $\mathrm{pH}$, temperature, dissolved oxygen, total dissolved solids, electrical conductivity, turbidity, colour and total suspended solids, total hardness, total alkalinity, chloride, fluoride, nitrates- $\mathrm{N}$, nitrites- $\mathrm{N}$, ammonium- $\mathrm{N}$, sulphates, total phosphate, sodium, calcium, magnesium and some heavy metals were analyzed. Total iron, lead, chromium, copper, zinc, manganese and cadmium were analyzed by atomic absorption spectrometry. Two of the basic biological parameters for drinking water such as faecal coliforms and salmonella were analyzed by incubation followed by counting colony forming units (CFUs). Statistical presentations of data including cluster analysis, dendrograms and principal component analysis were used with the assistance of PAST software. Temperature, $\mathrm{pH}$, TDS dissolved oxygen, cations, anions (chemical parameters) and salmonella, faecal coliforms were the major contributing parameters to gravity flow water's quality variations during both seasons. Values of $\mathrm{pH}$ ranged between 3.78 and 4.84 from March to August in all study sites and they were consistently below the WHO permissible $\mathrm{pH}$ range of 6.5 - 8.5. Total suspended solids ranged between 0.66 and $2.17 \mathrm{mg} \cdot \mathrm{L}^{-1}$ and were above the recommended WHO limit of zero value in all study sites. Salmonella and faecal coliforms colonies were present in scaring numbers in the wet season. In March, salmonella counts at Kacuro (14 CFU) and Kanjobe (128 CFU) while faecal coliforms counts at Kacuro (515 CFU) and Kanjobe (228 CFU). The findings of this study call for special attention when using gravity flow water.
\end{abstract}




\section{Keywords}

Temporal, Spatial, Seasonal Variations, Gravity Flow Water, Physical, Chemical, and Biological Parameters

\section{Introduction}

Achieving efficient and cost effective water treatment methods is key for human survival and development, thus water management is a current global concern (Juneja and Chaudhary, 2013) [1]. Gravity flow water is groundwater which has been diverted and piped to nearby communities to sustain all human activities, particularly in hilly areas like in Kigezi highlands, Uganda. Water issuing from springs and other underground sources can be safe in most areas (Macwelch, 2015) [2]. However, pollutants which do not break down easily may infiltrate and accumulate in groundwater aquifers and eventually make their way into groundwater plumes which feed gravity flow water sources. Groundwater is found in weathered portions, along the joints and fractures of the rocks (Rajappa et al., 2011) [3] from where it flows by means of gravity. Here, groundwater is developed into gravity flow water in hilly areas and piped to the community living within a handy radius from the main source. Water flow is maintained by the force of gravity and pressure generated as a product of height of water in reservoir $\mathrm{x}$ density of water $\mathrm{x}$ gravitational force (hpg) in the tank.

In gravity flow water schemes, gravity forces water stored in tanks to go down by its own weight inside the pipes and run out from the taps. This system works only if the pipes and taps are at a lower level than the water level at the starting point (Bouman, 2014) [4]. Gravity flow water systems are often the only feasible alternative for many rural areas at the present time and in many countries; a major portion of the funds available for water systems is allocated to gravity flow water systems. However, field inspections of completed projects and the literature indicate that there is a lack of capable design personnel and a substantial number of systems do not function properly due to the poor design (Faiia, 1982) [5]. In Hitosa, Ethiopia, 31 communities work together to operate and maintain 122 tap stands and $140 \mathrm{~km}$ of pipeline. Each community has two representatives on the Water Management Board which manages the Water Administration Office, employing 74 staff. All ongoing costs of the scheme are met by the water tariff (Silkin, 1998) [6].

There were no water tariffs in Kyanamira sub-county, Kabale District, in 2014 to assist management to maintain gravity flow water schemes because some people were poor and might fail to pay the tariffs. Rural water developers need to design a more improved gravity flow water system to enhance safety of gravity flow water as many rural people drink this water instantly at the tap site (see Figure 1).

Due to the nature of terrain, rainfall seasonal variations, population density, development and agricultural related activities, etc. in some areas; underground water sources should be considered "dirty". Disinfection methods such as filtra- 


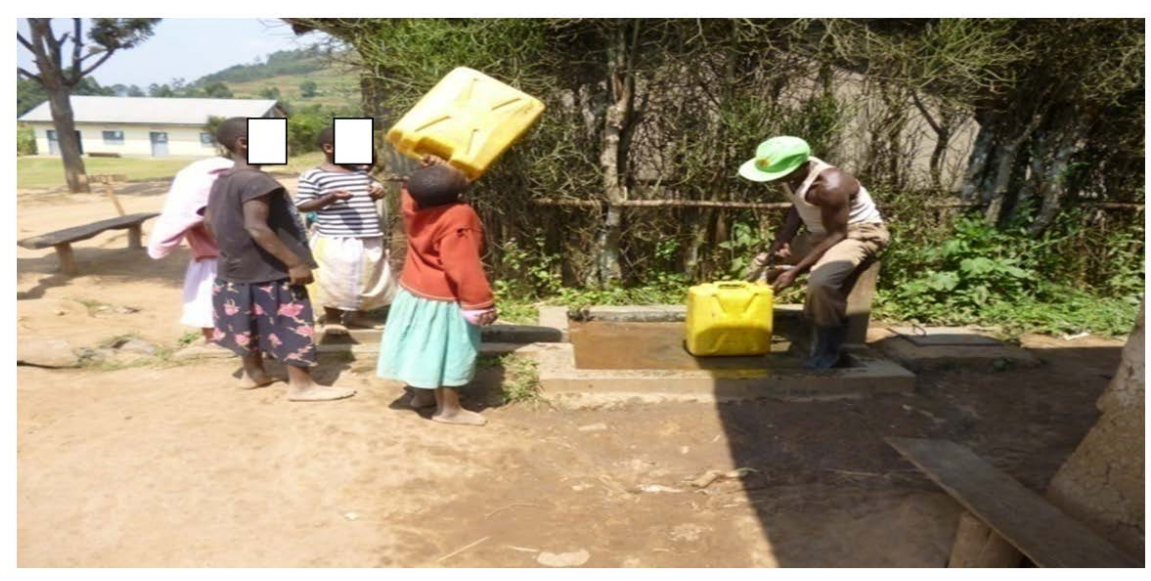

Figure 1. School kids drinking untreated gravity flow water at one of the taps of Kacuro gravity flow water system.

tion coupled with ultra violet disinfection especially in tropical regions may be included in gravity flow water systems to safeguard humans from unpredictable hazards.

Globally, groundwater provides about $50 \%$ of the current potable water supplies, $40 \%$ of the demand of self-supplied industry and $20 \%$ of water use in irrigated agriculture (UNESCO, 2003) [7]. Groundwater provides more than $40 \%$ of California's drinking water (Dawson and Kenneth, 2012) [8]. To protect this vital resource, the State of California created the Groundwater Ambient Monitoring and Assessment (GAMA) Programme. GAMA's priority is to evaluate the quality of untreated groundwater in the Indian wells valley of California. A similar programme to periodically evaluate the quality of gravity flow water and/or fresh groundwater sources in Kabale District, Uganda is missing.

Uganda has a total area of 241,500 Sq. $\mathrm{km}$. Out of this, $15.3 \%$ is open water, $3.0 \%$ permanent wetlands and $9.4 \%$ seasonal wetlands and over 162 freshwater lakes and numerous rivers. Groundwater provided $80 \%$ or more of the water supply in Uganda, especially in the rural areas (Danert et al., 2001) [9].

The increasing need of water for the growing population in Kabale District, Uganda requires implementation of good water quality regulatory policies. The main source of water for drinking, domestic, agricultural and industrial activities in Kabale District is groundwater supplied via gravity flow water pipes. During the wet season gravity flow water quality deteriorates as it emerges with its colour greatly changed. This may be due to human practices such as digging the unprotected surroundings of the gravity flow water sources and construction of deep pit latrines which may leak into groundwater aquifers and /or overflowing during heavy rains and gain access into groundwater later. Agrochemicals, hazardous wastes, etc. may enter groundwater and eventually make their way into plumes that supply gravity flow water and affect its quality negatively.

Nonetheless, there is no gravity flow water quality monitoring program to track temporal and spatial variations in Kabale district, Uganda. It was thus timely to investigate temporal and spatial variations in gravity flow water quality, as it 
indirectly reveals the status of groundwater and public health in Kabale district, Uganda.

Temporal and spatial seasonal variations in groundwater quality directly determine gravity flow water quality as pollutant loadings differ seasonally (runoff -high during wet season and low during dry season). During the wet season materials (eroded organic matter) transported to the groundwater aquifers may undergo eutrophication reactions. Eutrophication reactions in the gravity flow water systems (mainly in the reservoir) may affect water quality parameters such as increase in temperature favours microbial proliferation, alter the rate of adsorption and desorption processes, solubility of gases (decreasing dissolved oxygen), dissolution and transportation of materials (agrochemicals). Eutrophication reactions lower $\mathrm{pH}$ rendering gravity flow water acidic and low $\mathrm{pH}$ values enhance some of the effects like solubility in gravity flow water hence making it unsuitable for all human activities.

During the dry season, the rate of groundwater flow is high because of the small volume of water running from the groundwater aquifers in big volume waterways containing cold air. The high flow rate lowers temperature due water mixing with cold air in the gravity flow water pipes. In this case, gravity flow water mixes well with oxygen but again it may dissolve some inorganic pollutants from rocks along its way due to high kinetic energy being a function of high velocities of the water molecules contacting the rocks.

Changes in water quality parameters and their interactions vary from place to place in the direction of time. The following processes may take place in the gravity flow water reservoir tank at different rates depending on season and place of origin of gravity flow water. Therefore, every gravity flow water source needs to be monitored always as the sources of pollutants in groundwater aquifers are unpredictable. In addition, there is lack of data regarding the quality of the gravity flow water used in Kabale District and perhaps elsewhere in Uganda. Hence, there is need for water quality monitoring program-for identifying and tracking temporal and spatial gravity flow water quality changes in Kabale District, Uganda.

Processes such as dissolution, adsorption, desorption, transformation and eutrophication in gravity flow water reservoirs may take place due to interactions between physical, chemical (organic and inorganic constituents) and biological parameters in water confined in the reservoir. Products resulting from the occurence of these processes may accumulate in the sediment material at the bottom of water reservoir.

For example, at night all taps supplied by one gravity flow water tank may be closed. This allows water to overflow from near the top of the reservoir. But, water that actually overflows may be of better quality than the water that remains near the bottom of the tank. This is due to interchange of transformation products between the settled water and the sediment material. The bottom water is again very close to the pipes conveying it to the taps where people will fetch from. It is therefore timely for drinking water developers to design gravity flow 
water treatment methods to safeguard people from unpredictable hazards that may occur due to some sort of chemistry and /or contamination of groundwater. The named processes and interchange of materials between the sediment and gravity flow water in the reservoir affect its chemistry and more so when effects of rainfall seasonal variations are involved.

\section{Materials and Methods}

\subsection{Study Area}

Temporal and spatial seasonal variations in gravity flow water were studied in samples collected from the study sites (Kigata, Kihanga, Kacuro, Kitibya and Kanjobe) located in Kyanamira Sub-County; Kabale District, Uganda (Figures $2(a)-(c))$. The study principally determined the quality of gravity flow water by
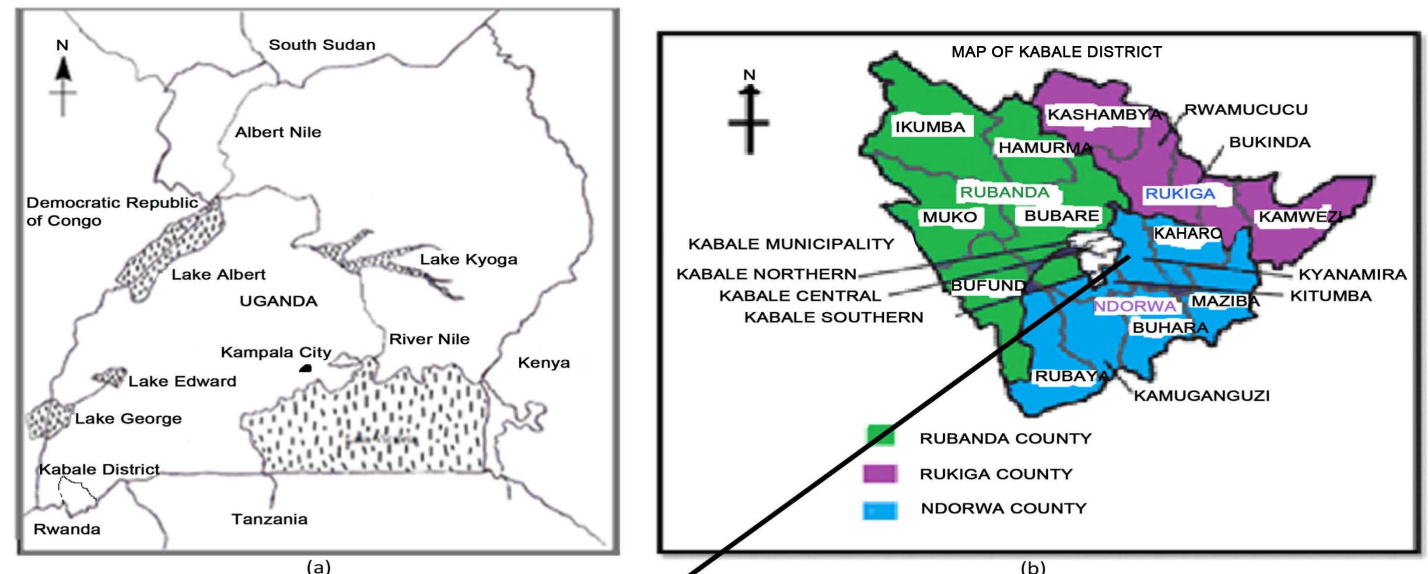

MAP OF KYANAMIRA SUB-COUNTY SHOWING STUDY SITES
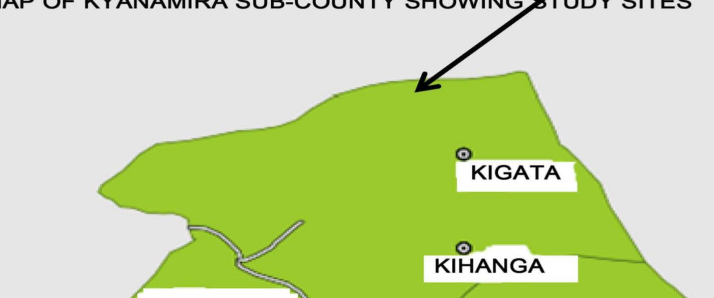
OLD KABALEMBARARA ROAD
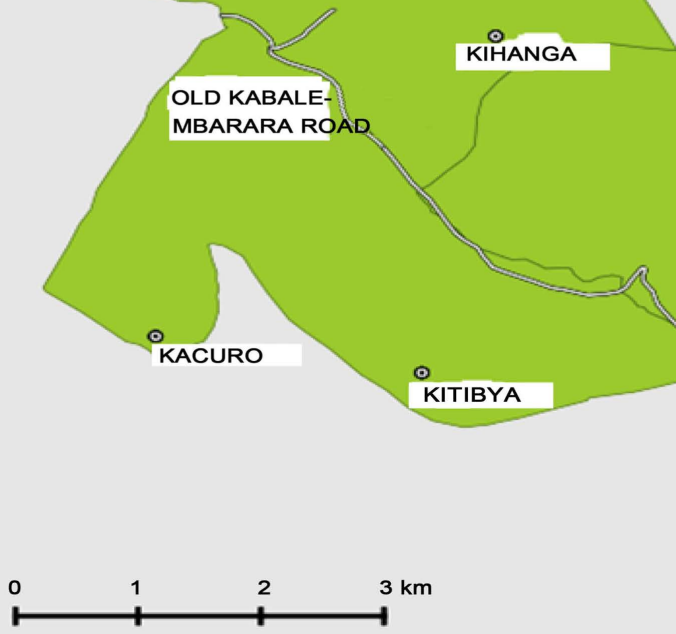

(c)

Figure 2. (a) Map of Uganda indicating the location of Kabale District; (b) Map of Kabale District indicating the location of Kyanamira sub-county; (c) Map of the study area. 
quantitative analysis of physical, chemical and biological parameters in the named study sites during the dry season (March-May) and wet season (June-August) in 2014. This study generated baseline data regarding temporal and spatial seasonal variations in physical, chemical and biological parameters. This study showed how the quality of gravity flow water used for all domestic activities and agriculture is affected in Kabale District, Uganda.

\subsection{Sample Collection}

Gravity flow water samples were collected from taps fed by pipes from gravity flow water reservoirs containing water from natural underground water slopes in the study area during wet season (March-May) and dry season (June-August) in 2014. The samples were obtained from Kigata, Kacuro, Kihanga, Kitibya and Kanjobe study sites located in Kyanamira Sub-County, Uganda. The samples were sealed and labelled properly. Preservation of samples was done as per the standard procedures (APHA, 1992) [10]. Three sub-samples from each location were collected at different times in one day per month from March to August, 2014. The three sub-samples from each study site were then mixed to obtain representative samples suitable for analysis. For the determination of biological parameters, samples were collected in sterile bottles of $200 \mathrm{~mL}$ capacity during both wet and dry seasons. The samples were kept in ice box and immediately taken to the laboratory for analysis.

\subsection{Analysis}

Temperature, $\mathrm{pH}$, electrical conductivity, dissolved oxygen and total dissolved solids of gravity flow water samples were measured using a multi-meter ( $\mathrm{HACH}$ model) at each study site. Different analytical methods were used in determination of other water quality parameters in the gravity flow water samples obtained from the five different water tank reservoirs for a period of six months. The study assessed physical, chemical and biological parameters of gravity flow water samples such as temperature, $\mathrm{pH}$, electrical conductivity, total dissolved solids, turbidity, dissolved oxygen, total alkalinity, total hardness, chloride, fluoride, phosphate, heavy metals, faecal coliforms and salmonella.

Standard sampling and analytical techniques were followed as suggested by Vogel's (1989) [11] and APHA, (1998) [12]. Water samples for chemical analysis were filtered through a hand-held Hanna filter system using a $0.45 \mathrm{~mm}$ cellulose filter paper (Advantec MFS Inc.) and collected in a $500 \mathrm{~mL}$ clean HDPE bottle. Two aliquots (one $500 \mathrm{~mL}$ and the other $125 \mathrm{~mL}$ ) were collected at each site; one aliquot $(125 \mathrm{~mL})$ was acidified to lower its $\mathrm{pH}$ to 2 using ultrapure nitric acid and the other $(500 \mathrm{~mL})$ unacidified. The samples were then refrigerated at $4^{\circ} \mathrm{C}$ before chemical analysis.

Acidified aliquots were analysed for heavy metals and trace elements by atomic absorption spectrophotometry (AAS Model version 100 AAnalyst). Unacidified aliquots were analysed for major anions, colour, turbidity and total suspended solids by spectrophotometry (Model DR 2010). The experiments 
were done in triplicates to ensure reliability of the results. Sample batches were regularly interspersed with standards and blanks and all data were corrected for instrument drift. Five points calibration curve was constructed for each element for the standards and the unknown concentration of the analytes in the samples were easily obtained by referring to it. The values obtained were compared with WHO (1993) [13] recommended limits for the elements under consideration. The determination of water quality parameters was carried out using various analytical methods (see Table 1).

\section{Results and Discussion}

The temporal and spatial seasonal variations in quality of gravity flow water were determined to assess its suitability for domestic and agricultural activities from March to August, 2014. The quality of gravity flow water was determined in terms of the water quality parameter measurements which gave values that were compared with those recommended for proper functioning of the biological systems of human beings (see Table 2). Although many of the physico-

Table 1. List of parameters and analytical methods used in the study.

\begin{tabular}{|c|c|c|}
\hline Parameter & Unit & Analytical method/instrument \\
\hline Temperature & ${ }^{\circ} \mathrm{C}$ & Thermometer \\
\hline $\mathrm{pH}$ & - & $\mathrm{pH}$ meter \\
\hline Colour & PtCo & Spectrophotometry \\
\hline Turbidity & NTU & Spectrophotometry \\
\hline Dissolved oxygen (DO) & $\mathrm{mg} \cdot \mathrm{L}^{-1}$ & Multi-meter \\
\hline Electrical conductivity & $\mu \mathrm{s} \cdot \mathrm{cm}^{-1}$ & Multi-meter \\
\hline Total alkalinity & $\mathrm{mg} \cdot \mathrm{L}^{-1}$ & Titrimetry \\
\hline Total hardness & $\mathrm{mg} \cdot \mathrm{L}^{-1}$ & EDTA titrimetry \\
\hline Total suspended solids & $\mathrm{mg} \cdot \mathrm{L}^{-1}$ & Gravimetric method \\
\hline Total dissolved solids & $\mathrm{Mg} \cdot \mathrm{L}^{-1}$ & Multi-meter \\
\hline Sodium & ppm & Flame photometry \\
\hline Chloride & ppm & Mercurimetric titrimetry \\
\hline Magnesium & $\mathrm{mg} \cdot \mathrm{L}^{-1}$ & Titrimetry \\
\hline Calcium & $\mathrm{mg} \cdot \mathrm{L}^{-1}$ & Titrimetry \\
\hline Sulphates & $\mathrm{mg} \cdot \mathrm{L}^{-1}$ & Atomic absorption spectrophotometry \\
\hline Nitrites & $\mathrm{mg} \cdot \mathrm{L}^{-1}$ & Atomic absorption spectrophotometry \\
\hline Orthophosphate $\left(\mathrm{PO}_{4}^{3-}-\mathrm{P}\right)$ & $\mathrm{mg} \cdot \mathrm{L}^{-1}$ & $\begin{array}{l}\text { Ammonium molybdate ascorbic } \\
\text { acid reduction method }\end{array}$ \\
\hline Nitrate $\left(\mathrm{NO}_{3}-\mathrm{N}\right)$ & $\mathrm{mg} \cdot \mathrm{L}^{-1}$ & Spectrophotometry \\
\hline Ammonia $\left(\mathrm{NH}_{3}-\mathrm{N}\right)$ & $\mathrm{mg} \cdot \mathrm{L}^{-1}$ & Spectrophotometry \\
\hline Total hardness & $\mathrm{mg} \cdot \mathrm{L}^{-1}$ & Titrimetry \\
\hline Fluoride & $\mathrm{mg} \cdot \mathrm{L}^{-1}$ & Spectrophotometry \\
\hline Total iron & $\mathrm{mg} \cdot \mathrm{L}^{-1}$ & Spectrophotometry \\
\hline Heavy metals ( $\mathrm{Zn}, \mathrm{Mn}, \mathrm{Cu}, \mathrm{Cd}, \mathrm{Pb}$ and $\mathrm{Cr}$ ) & ppm & Atomic absorption spectrophotometry \\
\hline Salmonella & CFU & Membrane filtration technique \\
\hline Faecal coliforms & CFU & Membrane filtration technique \\
\hline
\end{tabular}

Source: Vogel, (1989) [11] and Greenberg, (1992) [14]. 
Table 2. Mean parameter values recorded for each study site from March to August, 2014 .

\begin{tabular}{|c|c|c|c|c|c|c|c|}
\hline Parameters & Units & Kigata & Kacuro & Kihanga & Kitibya & Kanjobe & WHO limits \\
\hline Temperature & ${ }^{\circ} \mathrm{C}$ & 21.00 & 21.15 & 20.9 .00 & 21.80 & 20.30 & Not specified \\
\hline Colour & $\mathrm{PtCoU}$ & 9.0 & 2.8 & 6.0 & 8.5 & 7.3 & 15.0 \\
\hline Turbidity & NTU & 3.70 & 0.83 & 1.83 & 1.83 & 1.50 & 3.00 \\
\hline TDS & $\mathrm{mg} \cdot \mathrm{L}^{-1}$ & 141.30 & 74.25 & 71.83 & 44.38 & 53.47 & 1000.00 \\
\hline TSS & $\mathrm{mg} \cdot \mathrm{L}^{-1}$ & 2.17 & 0.83 & 1.33 & 1.50 & 0.66 & 0.00 \\
\hline $\mathrm{pH}$ & - & 3.78 & 4.52 & 4.68 & 4.84 & 4.81 & $6.5-8.5$ \\
\hline $\mathrm{EC}$ & $\mu \mathrm{S} \cdot \mathrm{cm}^{-1}$ & 281.8 & 158.8 & 147.9 & 93 & 104.8 & 400 \\
\hline Manganese & $\mathrm{mg} \cdot \mathrm{L}^{-1}$ & 0.11 & 0.002 & 0.096 & 0.034 & 0.034 & 0.4 \\
\hline Zinc & $\mathrm{mg} \cdot \mathrm{L}^{-1}$ & 0.024 & $\mathrm{Nd}$ & 0.009 & 0.186 & 0.023 & 3 \\
\hline Lead & $\mathrm{mg} \cdot \mathrm{L}^{-1}$ & $\mathrm{Nd}$ & $\mathrm{Nd}$ & $\mathrm{Nd}$ & $\mathrm{Nd}$ & $\mathrm{Nd}$ & 0.01 \\
\hline Iron & $\mathrm{mg} \cdot \mathrm{L}^{-1}$ & 0.04 & 0.02 & 0.042 & 0.083 & 0.058 & 1 \\
\hline Chromium & $\mathrm{mg} \cdot \mathrm{L}^{-1}$ & $\mathrm{Nd}$ & $\mathrm{Nd}$ & $\mathrm{Nd}$ & $\mathrm{Nd}$ & $\mathrm{Nd}$ & 0.01 \\
\hline Cadmium & $\mathrm{mg} \cdot \mathrm{L}^{-1}$ & $\mathrm{Nd}$ & $\mathrm{Nd}$ & $\mathrm{Nd}$ & $\mathrm{Nd}$ & $\mathrm{Nd}$ & 0.003 \\
\hline Copper & $\mathrm{mg} \cdot \mathrm{L}^{-1}$ & $\mathrm{Nd}$ & $\mathrm{Nd}$ & $\mathrm{Nd}$ & $\mathrm{Nd}$ & 0.002 & 2 \\
\hline Sodium & $\mathrm{mg} \cdot \mathrm{L}^{-1}$ & 25.76 & 17.76 & 16.64 & 4.56 & 5.37 & 200 \\
\hline Calcium & $\mathrm{mg} \cdot \mathrm{L}^{-1}$ & 16.33 & 12.8 & 18.77 & 15 & 15.2 & 75 \\
\hline Magnesium & $\mathrm{mg} \cdot \mathrm{L}^{-1}$ & 11.88 & 10.87 & 7.43 & 8.64 & 9.09 & 150 \\
\hline Chloride & $\mathrm{mg} \cdot \mathrm{L}^{-1}$ & 42.46 & 22.5 & 14.24 & 3.55 & 8.69 & 250 \\
\hline Sulphate & $\mathrm{mg} \cdot \mathrm{L}^{-1}$ & 55.67 & 9.5 & 33 & 14.67 & 14 & 250 \\
\hline $\mathrm{TH}$ & $\mathrm{mg} \cdot \mathrm{L}^{-1}$ & 89.67 & 76.67 & 73 & 73 & 75.33 & 500 \\
\hline TA & $\mathrm{mg} \cdot \mathrm{L}^{-1}$ & 5.67 & 14 & 7.67 & 8.67 & 8.67 & 500 \\
\hline DO & $\mathrm{mg} \cdot \mathrm{L}^{-1}$ & 2.6 & 2.81 & 2.21 & 4.35 & 2.53 & $8-10$ \\
\hline Phosphate & $\mathrm{mg} \cdot \mathrm{L}^{-1}$ & 0.128 & 0.042 & 0.113 & 0.063 & 0.04 & 0.1 \\
\hline Nitrate & $\mathrm{mg} \cdot \mathrm{L}^{-1}$ & 0.005 & 0.002 & 0.002 & 0.003 & 0.005 & 10 \\
\hline Nitrite & $\mathrm{mg} \cdot \mathrm{L}^{-1}$ & 0.006 & 0.005 & 0.004 & 0.006 & 0.005 & 3 \\
\hline Ammonia & $\mathrm{mg} \cdot \mathrm{L}^{-1}$ & 0.042 & 0.028 & 0.04 & 0.033 & 0.033 & 1.5 \\
\hline Fluoride & $\mathrm{mg} \cdot \mathrm{L}^{-1}$ & 0.295 & 0.52 & 0.61 & 0.26 & 0.295 & 1.5 \\
\hline Salmonella & $\mathrm{CFU}$ & 2 & 298 & 4 & 64 & 117 & 0 \\
\hline Faecal coliforms & CFU & 0 & 33 & 0 & 3 & 190 & 0 \\
\hline
\end{tabular}

$\mathrm{Nd}=$ Not detected

chemical and biological constituents of water are very essential for growth and health of humans, they have adverse effects on human health when present in excess.

The results of physico-chemical and biological analysis of gravity flow water samples from each study site recorded in Table 2 were compared with permissible WHO limits for drinking water and populace health purposes. 


\subsection{Clusters of Spatial Variations in Gravity Flow Water Quality}

Cluster analysis yielded a dendrogram (see Figure 3) which grouped the five gravity flow water sources into four statistically significant clusters at $\left(D_{\text {link }} /\right.$ $\mathrm{D}_{\max }$ ). Kacuro was placed alone in the dendrogram (Cluster I) implying that it is not similar to any other study site under investigation. Cluster II contains the other four study sites showing some level of similarity in their gravity flow water quality that is, at Kigata, Kitibya, Kihanga and Kanjobe study sites. Cluster III encompasses three out of the four study sites showing an increased level of similarity in gravity flow water quality at Kigata, Kitibya and Kihanga. Cluster IV consists of two out of three study sites showing more increased level of similarity in quality of gravity flow water at Kihanga and Kitibya. Kacuro (Cluster I) was clustered alone showing that its gravity flow water quality reasonably differed from the quality of other gravity flow water sources.

Gravity flow water sources were clustered together according to how they are similar in terms of the factors that determine gravity flow water quality. Factors

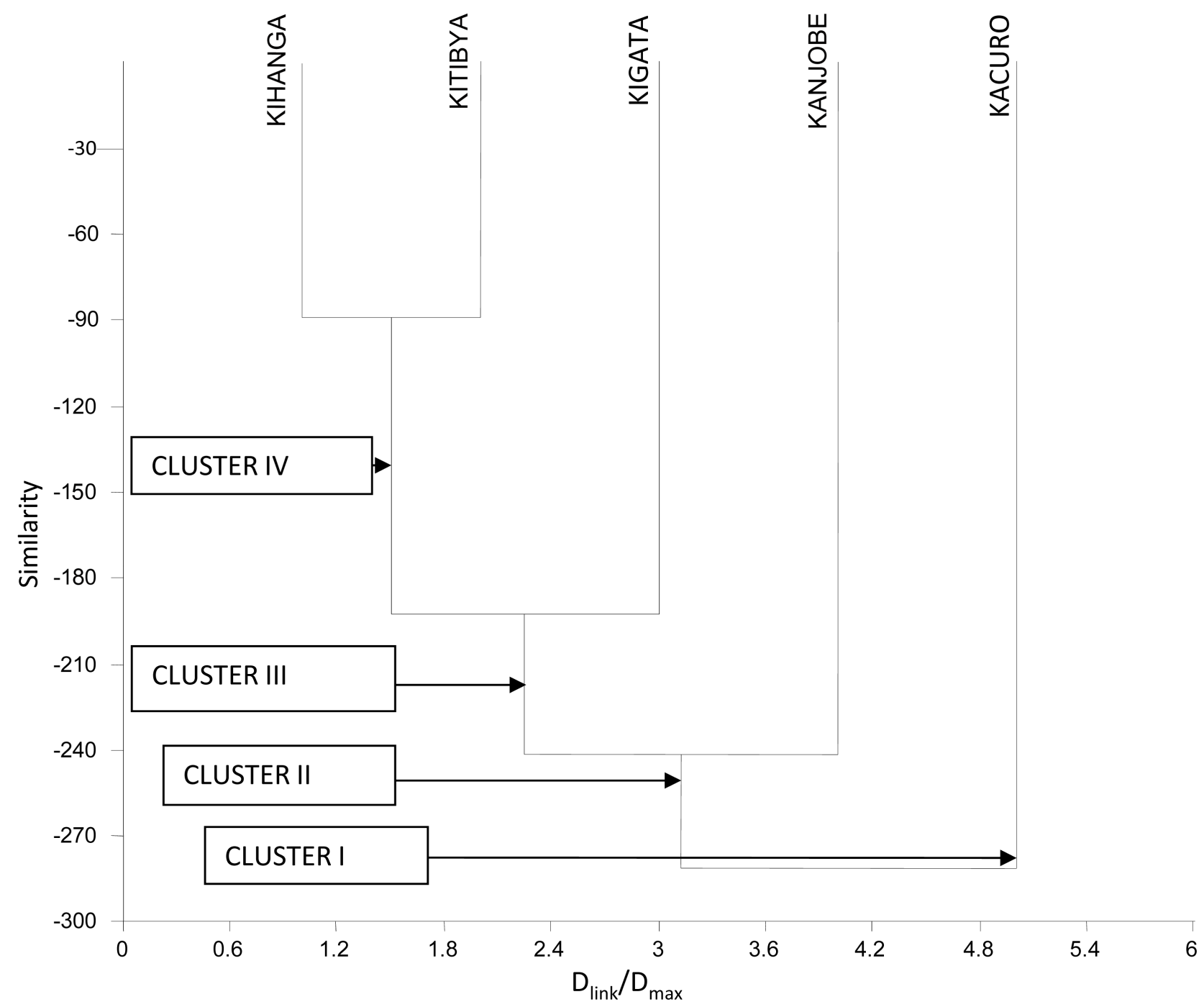

Figure 3. Dendrogram showing similarity of gravity flow water quality at different study sites, 2014 
such as geological processes, $\mathrm{pH}$ of the water, temperature of water in the aquifers, content of organic matter present, TDS, colour, etc. were the parameters used to cluster the study sites together.

\subsection{Principal Component Analysis}

Variable expression values (see Figure 4) show that salmonella and faecal coliforms dominated in gravity flow water at Kacuro and Kanjobe water sources, respectively. EC, TDS, chloride followed by other parameters considered in the study dominated in gravity flow water at Kigata, Kihanga and Kitibya. Conversely, Kigata, Kihanga and Kitibya had low variable expression values for salmonella and faecal coliforms.

The high faecal coliform and salmonella counts observed at Kanjobe and Kacuro, respectively, may be attributed to the age, quality and location of the gravity flow water systems; human practices such as inappropriate positioning of pit latrines and drainage of surface runoff into the groundwater aquifers which feed the gravity flow water source.

\subsection{Temporal Variations in Gravity Flow Water Quality}

The determination of temporal variations was done by means of Ward's method (Ishaku et al., 2011) to give squared Euclidean distances as a measure of similarity using cluster analysis (see Figure 5). Ward's method enabled an analysis of variance approach to evaluate the distances between the clusters in order to minimize the sum of squares of any two clusters (that can be formed at each step).

Figure 5 shows that Gravity flow water quality was clustered according to time (in months) of the study in which instant changes in gravity flow water quality were observed between successive months and more changes became

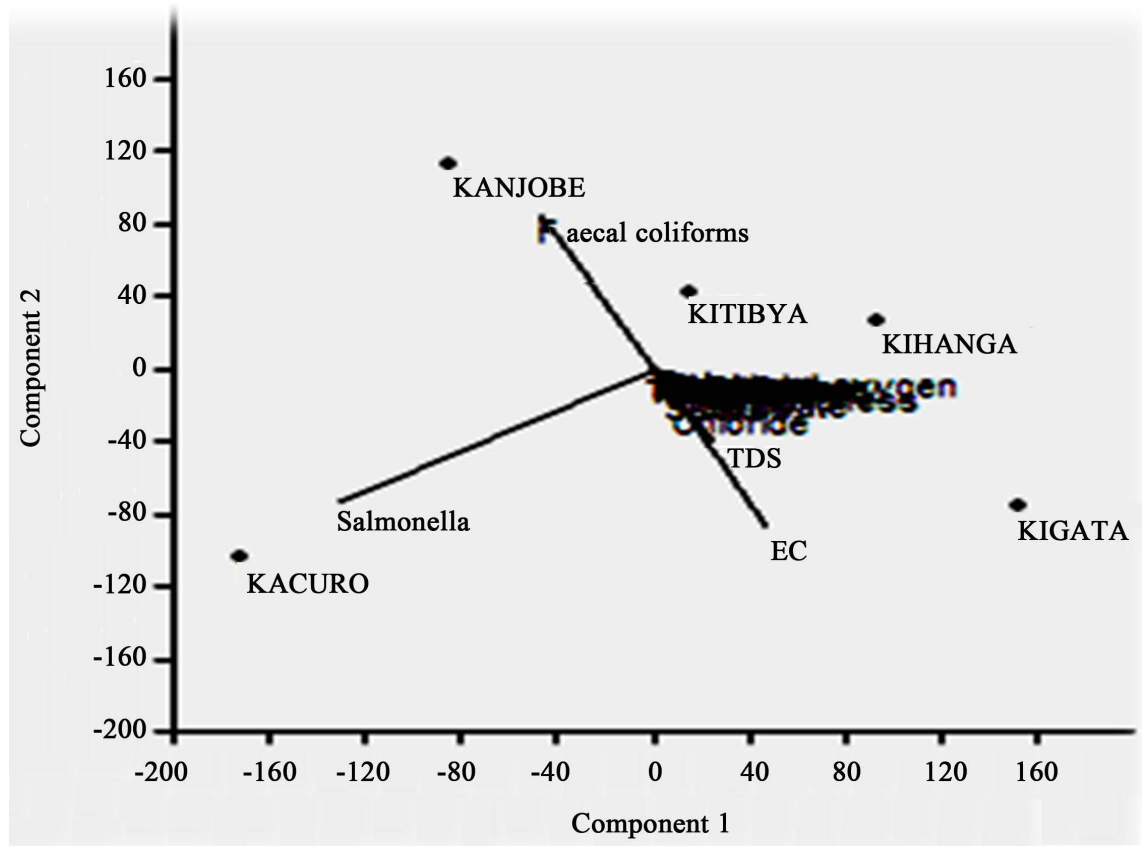

Figure 4. Principal component analysis of gravity flow water quality. 


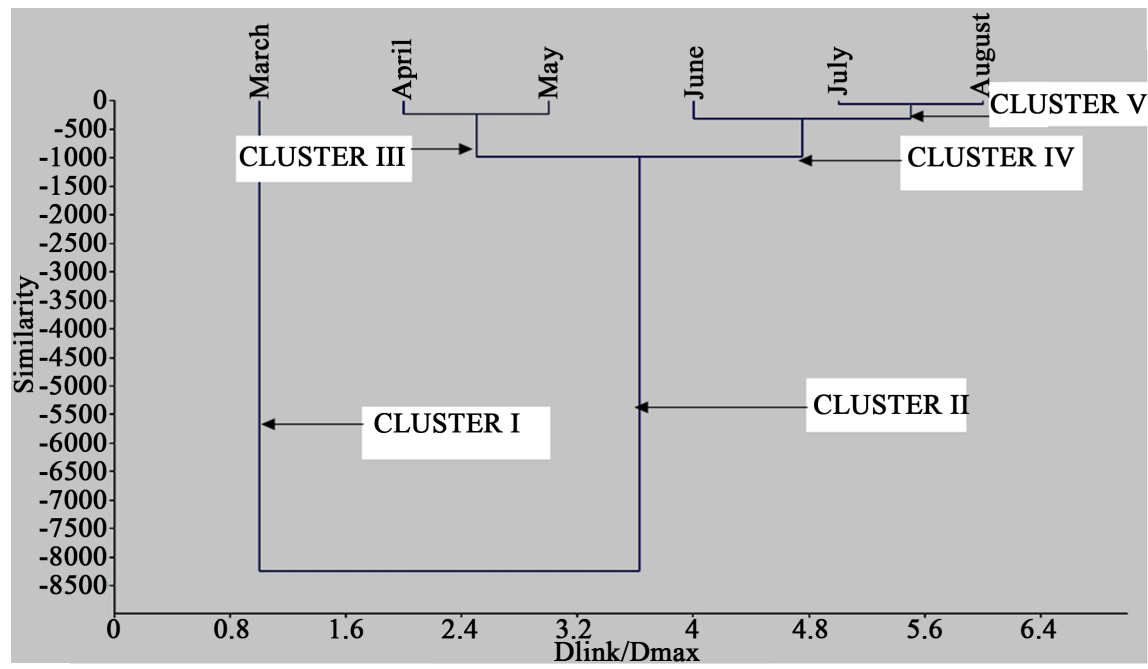

Figure 5. Temporal variations of gravity flow water quality from March to August, 2014.

apparent when results of the wet and dry seasons were compared. Cluster I shows that variable expression values of March were different from the variable expression values of other months (April, May, June, July and August). Cluster II branched to give clusters III and IV. Cluster III showed that April and May had more similar gravity flow water qualities. Cluster IV showed that June had different quality varaible expression values compared to July and August which were clustered together showing more similarity. The similarity in the quality of gravity flow water in Kyanamira sub-county, Kabale District, Uganda bases on the fact that during the months of June, July and August, a dry season is experienced in all study sites considered.

\subsection{Scatter Variations in Gravity Flow Water Quality}

The values of electrical conductivity (EC) and total dissolved solids (TDS) in gravity flow water varied reasonably during wet and dry seasons in 2014. The measurements of EC and TDS were used to draw a scatter diagram of the months showing their temporal arrangement informing about their similarirty in terms of quality in gravity flow water (see Figure 5).

\subsubsection{Variations in Quality of Gravity Flow Water from March to August, 2014}

Generally, EC and TDS variation values (see Figure 6) were low in the month of March, moderate in the months of May, June, July, and August while in the month of April, the values were considerably high. The high EC variations observed in April may be attributed to increased TDS values from dissolution of rocks, increased mobility of ions and infiltration of conducting compounds into the sources of gravity flow water since it was a rainy season.

\subsubsection{Variations in Quality of Gravity Flow Water during Wet Season}

The scatter diagram (see Figure 7) shows that both electrical conductivity (EC) and total dissolved solids (TDS) were low in the month of March and increased reasonably in the month of April followed by a low EC at relatively high TDS 


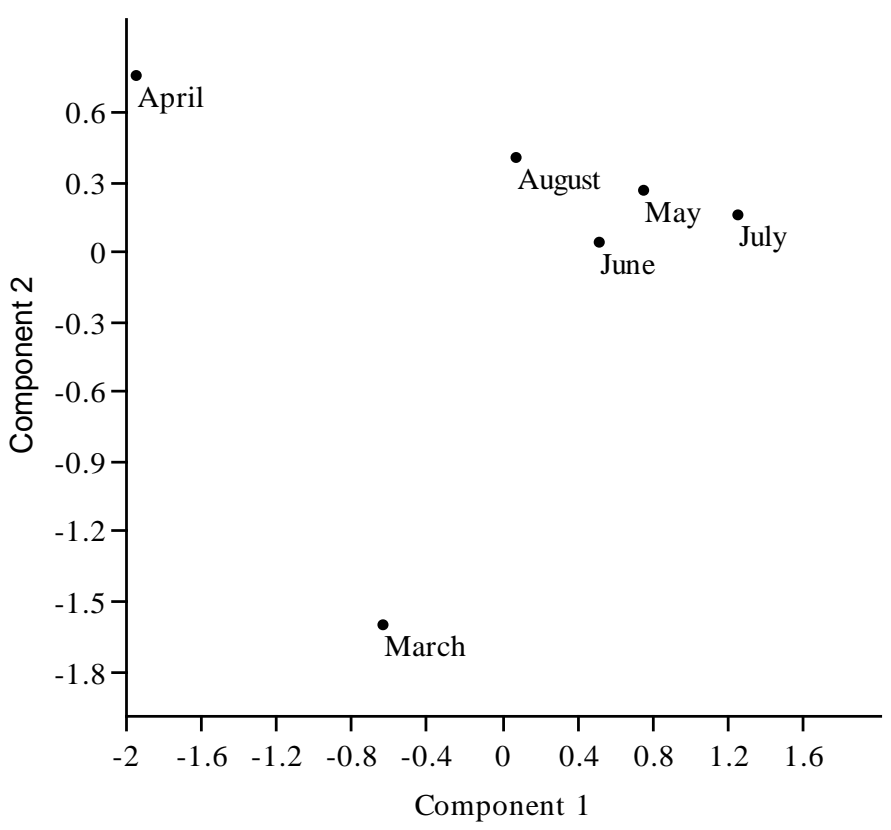

Figure 6. Scatter diagram showing temporal variations of EC versus TDS in gravity flow water quality from March to August, 2014.

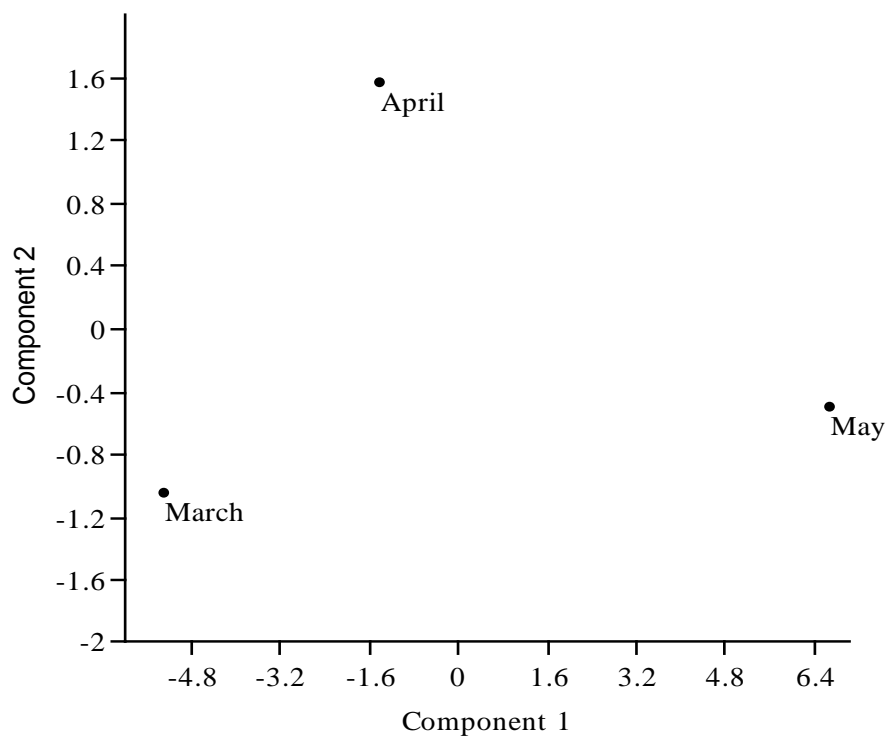

Figure 7. Scatter diagram showing temporal variations of EC versus TDS during the wet season.

values in the month of May. The values of EC and TDS in March were low because it marked the beginning of the wet season and the conducting constituents had not dissolved yet.

\subsubsection{Variations in Quality of Gravity Flow Water during Dry Season}

In May, however, conducting compounds had accumulated in the groundwater systems which feed the gravity flow water sources. This led to high values of EC and TDS of the gravity flow water. The low EC and high TDS values could have been due to the discharge, deposition, precipitation, etc, of the conducting con- 
stituents in the gravity flow water, leaving soluble but less conducting species which led to high TDS values in the month of May, 2014.

Low EC values and relatively high values of TDS in June, 2014 were observed (see Figure 8). In July, the EC values were high as compared to those of June but TDS values were low. In August, however, both EC and TDS values were high. The variations in EC and TDS in June were due to low levels of conducting chemical species. In July, high EC values were due high levels of conducting constituents contained in low volumes of water since it was a dry season. In August, the high values of both EC and TDS were due to some rain that was received during the study and which could have diluted gravity flow water allowing deposited, precipitated, etc, and hence more conducting species to become mobile thus increasing TDS and EC values.

\subsubsection{Scree Plot}

The scree plot shows the eigenvalues on the $y$-axis and the number of factors on the X-axis. It always displays a downward curve (see Figure 9). The point where the slope of the curve is clearly leveling off (the "elbow") indicates the number of factors that should be generated by the analysis.

The scree plot displays the eigenvalues associated with a component or factor in descending order versus the number of the component or factor. Scree plots are used in principal components analysis and factor analysis to visually assess which components or factors explain most of the variability in the data. In this study, four latent factors were revealed according to the eigenvalues in the scree plot (see Figure 9).

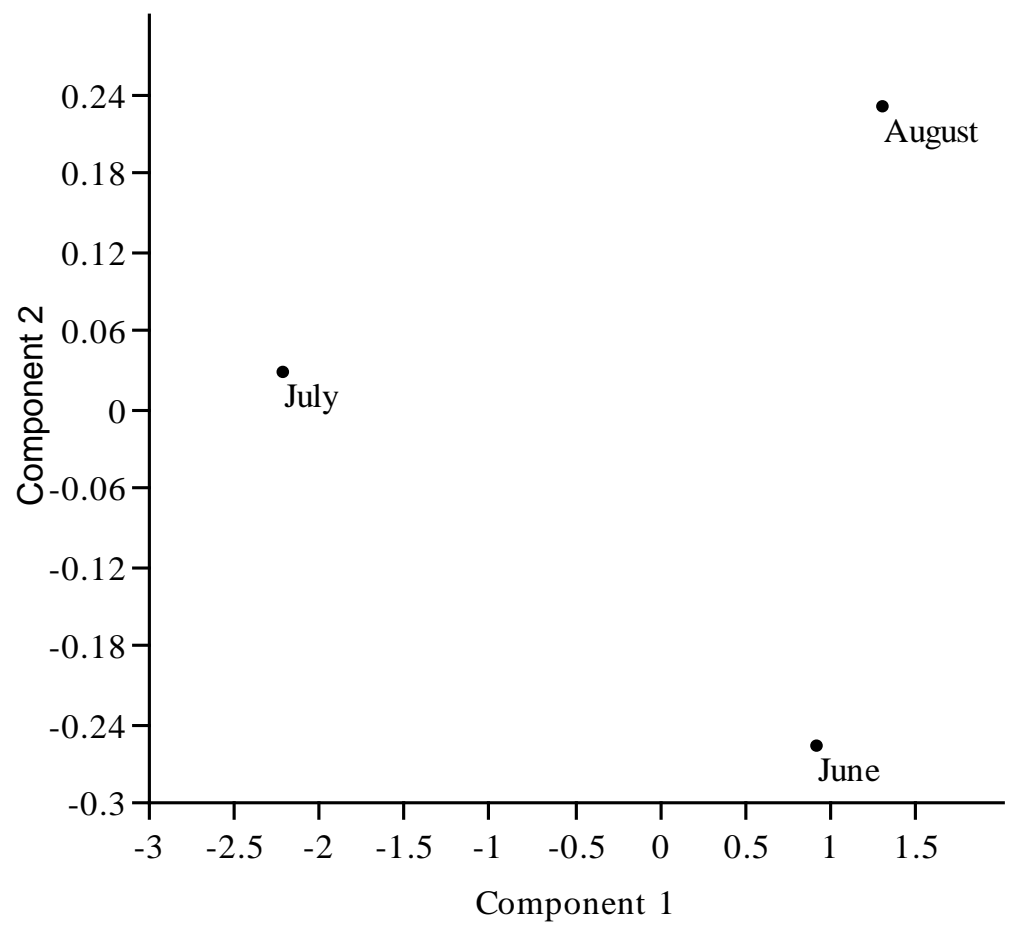

Figure 8. Scatter diagram showing temporal variation of EC versus TDS during dry season. 


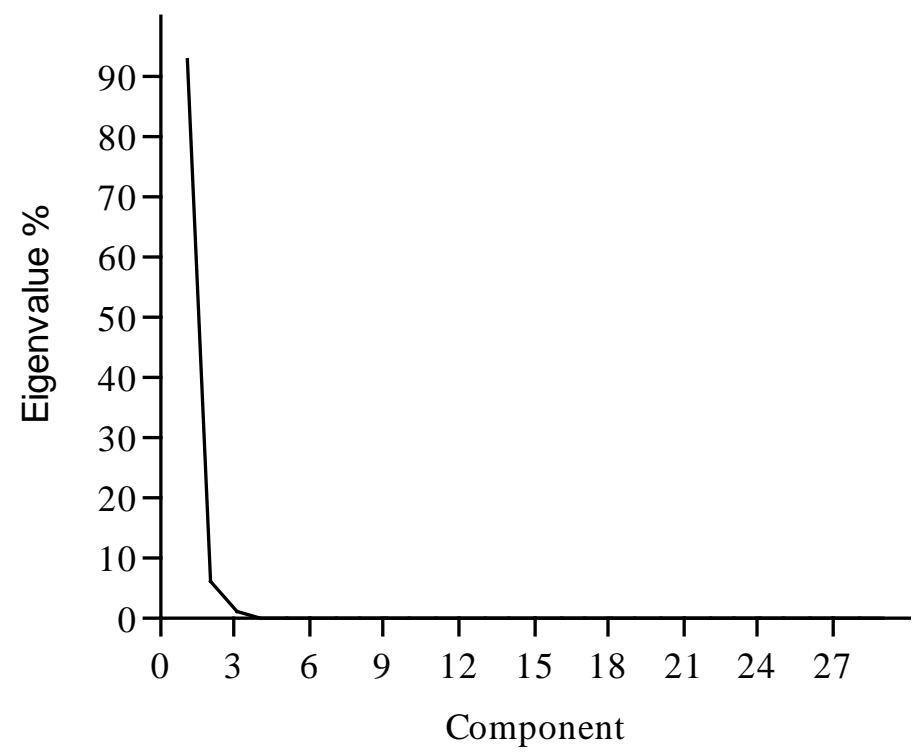

Figure 9. Scree plot showing similarity and distance indices in different months of the study.

\section{Conclusions}

The findings of the study showed the highest temperature in Kitibya in June, 2014 and the lowest temperature in Kanjobe in March, 2014. The lowest temperatures ranged between $19^{\circ} \mathrm{C}$ and $21^{\circ} \mathrm{C}$ and were recorded in March, 2014 for all study sites. Colour values of gravity flow water were higher in the wet season compared to dry season in all study sites. The lowest turbidity values were observed during the dry season in all study sites except Kigata site where the values tended to remain high. Results of the study indicated that Kigata had the highest TDS values throughout the study.

Values of total suspended solids fluctuated slightly increasing from the wet season (March-May) to the dry season (June-August) at Kigata, Kitibya and Kihanga; then slightly decreasing at Kacuro and Kanjobe study sites. It was observed that $\mathrm{pH}$ values generally increased from wet season to dry season. According to the $\mathrm{pH}$ values obtained during this study, gravity flow water was acidic and to make its quality inferior, the $\mathrm{pH}$ values were below the WHO permissible limits in all study sites. The electrical conductivity values consistently increased from wet season to dry season for all study sites and were within the WHO permissible limits. Results showed that the concentrations of all heavy metals were within the WHO recommended ranges. Kanjobe showed the highest concentrations of sodium, chloride, sulphates and total hardness. The results showed intolerable faecal coliforms in gravity flow water in all study sites. Similarly, salmonella species were detected in Kacuro, Kitibya and Kanjobe sites at alarming levels.

Hence, groundwater developers in Kabale District, Uganda need to put in place provisional measures such as spatial and temporal water quality monitoring programs to track and regulate water quality variations and so could be the case in other developing areas especially hilly ones elsewhere. 


\section{References}

[1] Juneja, T. and Chaudhary, A. (2013) Assessment of Water Quality and Its Effects on the Health of Residents of Jhunjhunu District, Rajasthan: A Cross Sectional Study. Journal of Public Health and Epidemiology, 5, 186-191.

[2] Macwelch, T. (2015) Survival Skills: Ways to Purify Water. Access to Safe Drinking Water Is Critical in Camping Or Survival Situations.

[3] Rajappa, B., Manjappa, S., Puttaiah, E.T. and Nagarajappa, D.P. (2011) Physico-Chemical Analysis of Underground Water of Harihara Taluk of Davanagere District, Karnataka, India. Advances in Applied Science Research, 2, 143-150.

[4] Bouman, D. (2014) Hydraulic Design for Gravity Based Water Schemes. 4.

[5] Faiia, A.S. (1982) Gravity Flow Water Systems: Practical Design Notes for Simple Rural Water Systems. 1.

[6] Silkin, T. (1998) Hitosa Water Supply: A People’s Project. 2.

[7] United Nations Education and Scientific Organisation, UNESCO (2003)

[8] Milby Dawson, B.J. and Belitz, K. (2012) Groundwater Quality in the Indian Wells Valley, California.

[9] Danert, K., Adekile, D. and Canuto, J.G. (2001) British Geological Survey, Groundwater Quality: Uganda.

[10] American Public Health Association (1992) Standard Methods for the Examination of Water and Wastewater, Washington DC, USA. 18th Edition.

[11] Vogel's Jeffery, G.H., Bassett, J., Mendham, J. and Denney, R.C. (1989) Textbook of Quantitative Chemical Analysis. 5th Edition, Wiley John \& Sons, Inc., New York.

[12] American Public Health Association, APHA (1998) American Water Works Association and Water Environment Federation, Standard Methods for the Examination of Water and Wastewater, American Public Health Association, Washington DC, USA.

[13] World Health Organisation (1993) Guidelines for Drinking Water Quality, Recommendations, Geneva.

[14] Arnold, G.E. (1992) Standard Methods for Examination of Water and Wastewater. 18th Edition, American Public Health Association.

\section{Submit or recommend next manuscript to SCIRP and we will provide best} service for you:

Accepting pre-submission inquiries through Email, Facebook, LinkedIn, Twitter, etc. A wide selection of journals (inclusive of 9 subjects, more than 200 journals)

Providing 24-hour high-quality service

User-friendly online submission system

Fair and swift peer-review system

Efficient typesetting and proofreading procedure

Display of the result of downloads and visits, as well as the number of cited articles

Maximum dissemination of your research work

Submit your manuscript at: http://papersubmission.scirp.org/

Or contact jwarp@scirp.org 